\title{
TOPLOTNA PROVODLJIVOST SUVOG I VLAŽNOG MATERIJALA ZIDOVA - VAŽAN UTICAJ NA ENERGETSKU EFIKASNOST OBJEKATA
}

\author{
Milan Kekanović ${ }^{1}$ \\ Dragoslav Šumarac ${ }^{2}$ \\ Karolj Kasaš ${ }^{3}$ \\ Arpad Čeh ${ }^{4}$
}

UDK: $691: 536.2 .022$

DOI:10.14415/konferencijaGFS 2016.043

Rezime: Ovaj rad ukazuje na vrlo važan detalj od koga zavisi energetska efikasnost objekata a to je stanje vlažnosti materijala kojim izolujemo objekte. Instrumenti starije generacije, merenje toplotne provodljivosti izvode isključivo u suvom stanju materijala. Tako dobijamo merenu toplotnu provodljivost $\lambda_{m}(\mathrm{~W} / \mathrm{mK})$ u suvom stanju $i$ indirektno procenjenu (iz tabela) računsku vrednost $\lambda_{r}(W / m K)$, za vlažno stanje materijala. Često se dešava da projektanti u proračunu slučajno ili namerno koriste $\lambda_{m}(\mathrm{~W} / \mathrm{mK})$ za suvo stanje materijala, što je manja vrednost koja daje veći otpor prelazu toplote $R\left(m^{2} K / W\right)$. Problem nastaje kada zimi materijal postaje vlažan sa većom provodljivošću toplote, što direktno negativno utiče na energretsku efikasnost objekata. Instrumenti nove generacije kao što je Isomet 2114, su u stanju da vrlo brzo i precizno izmere računsku vrednost $\lambda_{r}$ $(W / m K)$ za realno stanje vlažnosti materijala koja će stvarno u toku zime biti u zidovima objekata. Na taj način moguće je preciznije odrediti debljinu slojeva zida koji će zadovoljiti propisane vrednosti prelaza toplote $U\left(W / m^{2} K\right)$ za uslove realne vlažnosti materijala u zidovima.

Ključne reči: provodljivost, prenos toplote, energetska efikasnost

\section{UVOD}

Značaj podizanja energetske efikasnosti zgrada u Evropi, Srbiji, Mađarskoj i svetu je danas vrlo veliki. Zakonodavci su propisali uslove i klase energetske efikasnosti u smislu potrošnje energije za grejanje objekata. Ostvareni rezultati energetske efikasnosti nisu preterano zadovoljavajući čak ni u EU. U najvećem broju slučajeva zadovoljena je

\footnotetext{
${ }^{1}$ Milan Kekanović, dipl.inž.građ., Univerzitet u Novom Sadu, Građevinski fakultet Subotica, Kozaračka 2a, Subotica, Srbija, Tel: 024554 300, e - mail: kekec@gf.uns.ac.rs

${ }^{2}$ Dragoslav Šumarac, dipl.inž.građ., Univerzitet u Beogradu, Građevinski fakultet u Beogradu, Bulevar Kralja Aleksandra 73, 11000 Beograd, Srbija, Tel:+381113218544, e-mail: sumi@eunet.rs

${ }^{3}$ Karolj Kasaš, dipl.inž.tehn., Univerzitet u Novom Sadu, Građevinski fakultet Subotica, Kozaračka 2a,

Subotica, Srbija, Tel: 024554 300, e-mail: kkasas@gf.uns.ac.rs

${ }^{4}$ Arpad Čeh, dipl.inž.građ., Univerzitet u Novom Sadu, Građevinski fakultet Subotica, Kozaračka 2a, Subotica, Srbija, Tel: 024554 300, e - mail: ceh@gf.uns.ac.rs
} 
Contemporary achievements in civil engineering 22. April 2016. Subotica, SERBIA

najniža dopuštena C klasa potrošnje eneregije. [1] Razloga za takav rezultat ima više. U ovome radu mi analiziramo i ukazujemo na jedan razlog zbog kojeg može biti potrošnja energije veća od izračunate. To znači da se može desiti i dešava se da praktično ni najniže dopuštena $\mathrm{C}$ klasa nije zadovoljena. [4] Radi se o promeni termoizolacijskih sposobnosti u odnosu na stanje vlažnosti materijala u zidovima. Zavisno o kojim materijalima se radi za izradu izolacije zidova, ove vrednosti mogu praktično bitno da umanje energetsku efikasnost objekta koja može opasti i za više od $20 \%$. To znači da se vrlo lako može desiti da objekat ne zadovoljava isprojektovanu klasu objekta. Ne ispunjavanje sertifikovane energetske klase objekta povlači čitav niz problema vezanih za zakonske propise uz obavezu nadoknade štete kupcima nekretnina i investitorima takvih objekata.

\section{REZULTATI SPROVEDENIH MERENJA}

Rezultati merenja koja smo sproveli u laboratorijskim uslovima sa instrumentom Isomet 2114 na dve vrste materijala koji se koriste kod izgradnje nosivih spoljašnjih zidova, su vrlo zabrinjavajući. Analizirali smo punu opeku od pečene gline i Ytong blok od lakog gas betona.

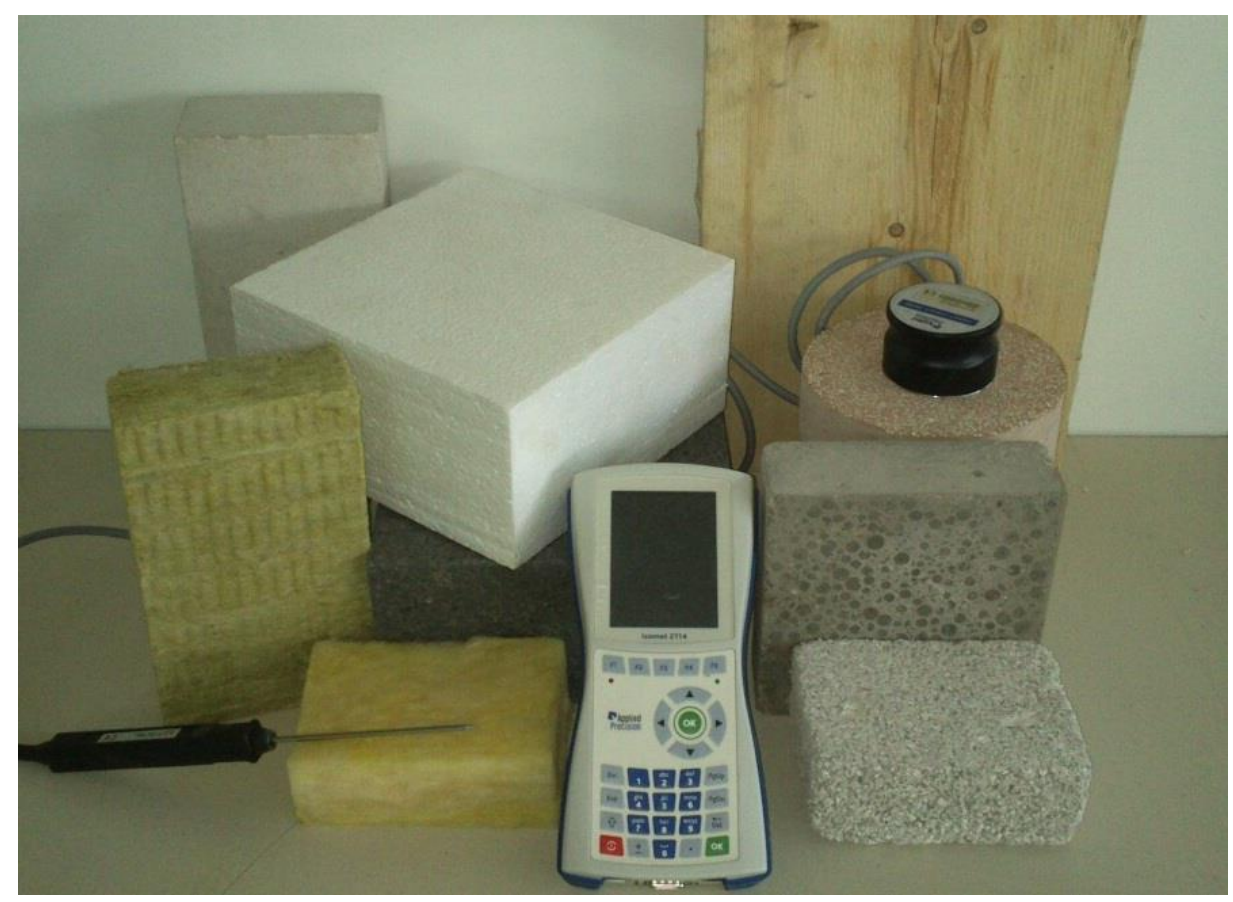

Slika 1. Uređaj Isomet 2114 za analizu termotehničkih osobina materijala 
Tabela 1. Zapreminske mase [ $\left.\mathrm{kg} / \mathrm{m}^{3}\right]$ i vlažnost [\%] uzoraka materijala od pečene opeke od gline i Ytong bloka od lakog gas betona

\begin{tabular}{|l|c|c|c|c|}
\hline Materijal & $\begin{array}{c}\text { Zapr.masa } u \\
\text { potpuno suvom } \\
\text { stanju }\left(\mathrm{kg} / \mathrm{m}^{3}\right)- \\
\text { vlažnost } \\
\text { materijala }(\%)\end{array}$ & $\begin{array}{c}\text { Zapr.masa } u \\
\text { prirodno suvoj } \\
\text { sredini } \\
\left(\mathrm{kg} / \mathrm{m}^{3}\right)- \\
\text { vlažnost } \\
\text { materijala }(\%)\end{array}$ & $\begin{array}{c}\text { Zapr.masa } u \\
\text { prirodno } \\
\text { vlažnoj sredini } \\
\left(\mathrm{kg} / \mathrm{m}^{3}\right)- \\
\text { vlažnost } \\
\text { materijala }(\%)\end{array}$ & $\begin{array}{c}\text { Zapr.masa } u \\
\text { potpuno } \\
\text { zasićenom } \\
\text { stanju }\left(\mathrm{kg} / \mathrm{m}^{3}\right) \text { - } \\
\text { vlažnost } \\
\text { materijala }(\%)\end{array}$ \\
\hline $\begin{array}{l}\text { Opeka } \\
\text { Ytong } \\
\text { blok }\end{array}$ & $1516-0 \%$ & $1570-3,56 \%$ & $1753-15,63 \%$ & $1910-26 \%$ \\
\hline
\end{tabular}

Zapreminska masa u prirodno suvoj sredini podrazumeva laboratorijske uslove sa temperaturom od $+20{ }^{0} \mathrm{C}$ i relativnom vlažnošću vazduha $55 \%$. Zapreminska masa $\mathrm{u}$ prirodno vlažnoj sredini podrazumeva spoljašnje uslove u jesenskom periodu godine. Potpuno zasićeno stanje podrazumeva postupno upijanje materijala u vodi. Iz rezultata se vidi da su i opeka i Ytong blokovi vrlo higroskopni materijali koji upijaju vodenu paru iz vazduha. Opeka ima kapilarne pore a Ytong blokovi su sačinjeni od kreča i cementa koji su vrlo higroskopni sa vrlo malim otporom difuziji vodene pare $\mu=2$ do 6 [2]. I jedan i drugi materijal ima podjednaku sposobnost upijanja vode do zasićenja, i to upijanje je između 26\% i 28\% ( Tabela 1). Neznatno veću vlažnost u suvoj sredini ima opeka. Vlažnost u spoljašnjim uslovima znatno veću ima Ytong. To je razumljivo jer $u$ spoljašnjim uslovima je bila veća relativna vlažnost i veoma mali otpor difuziji vodene pare kod Ytonga koji je upio čak $25,16 \%$ vode u obliku vodene pare iz vazduha. Opeka ima nešto veći otpor difuziji vodene pare koji se kreće $\mu=6$ do 12 [3]. Zbog toga je kapacitet kapilarnog upijanja vodene pare iz vazduha kod opeke u ovom slučaju za date vremenske uslove izmeren $15,63 \%$. Te vrednosti predstavljaju maksimum kapilarnog upijanja vodene pare iz vazduha koju može da upije pečena glina i Ytong blok u spoljnjim uslovima.

Tabela 2. Termotehničke karakteristike opeke

\begin{tabular}{|c|c|c|c|c|c|}
\hline $\begin{array}{c}\text { Zapreminska } \\
\text { masa } \\
\left(\mathrm{kg} / \mathrm{m}^{3}\right)\end{array}$ & $\begin{array}{c}\text { Vlažnost } \\
(\%)\end{array}$ & $\begin{array}{c}\text { Toplotna } \\
\text { provodljivost } \\
(\mathrm{W} / \mathrm{mK})\end{array}$ & $\begin{array}{c}\text { Povećanje } \\
\text { topl. } \\
\text { provodljivosti } \\
(\%)\end{array}$ & $\begin{array}{c}\text { Specifična } \\
\text { toplota c } \\
\left(\mathrm{MJ} / \mathrm{m}^{3} \mathrm{~K}\right)\end{array}$ & $\begin{array}{c}\text { Koeficijent } \\
\text { difuzije } \\
\text { toplote } \\
\left(\mathrm{m}^{2} / \mathrm{s}\right)\end{array}$ \\
\hline 1516 & 0 & 0,449 & 0 & 1,510 & $0,297 \times 10^{-6}$ \\
\hline 1590 & 3,56 & 0,547 & 2,18 & 1,520 & $0,360 \times 10^{-6}$ \\
\hline 1753 & 15,63 & 1,235 & 175,06 & 1,771 & $0,698 \times 10^{-6}$ \\
\hline 1875 & 26 & 1,345 & 199,55 & 1,831 & $0,756 \times 10^{-6}$ \\
\hline
\end{tabular}

Za navedena stanja vlažnosti, je relativno brzo, u periodu od samo 1 sat vremena urađeno tri merenja pomoću instrumenta najnovije generacije, Isomet 2114. Ponovljivost rezultata merenja je u dozvoljenim granicama i instrument je sam izračunao srednje vrednosti koje su prikazane u tabelama (Tabela 2. i Tabela 3.) 
Contemporary achievements in civil engineering 22. April 2016. Subotica, SERBIA

Tabela 3. Termotehničke karakteristike Ytong blokova

\begin{tabular}{|c|c|c|c|c|c|}
\hline $\begin{array}{c}\text { Zapreminska } \\
\text { masa } \\
\left(\mathrm{kg} / \mathrm{m}^{3}\right)\end{array}$ & $\begin{array}{c}\text { Vlažnost } \\
(\%)\end{array}$ & $\begin{array}{c}\text { Toplotna } \\
\text { provodljivost } \\
(\mathrm{W} / \mathrm{mK})\end{array}$ & $\begin{array}{c}\text { Povećanje } \\
\text { toplotne } \\
\text { provodljivosti } \\
(\%)\end{array}$ & $\begin{array}{c}\text { Specifična } \\
\text { toplota c } \\
\left(\mathrm{MJ} / \mathrm{m}^{3} \mathrm{~K}\right)\end{array}$ & $\begin{array}{c}\text { Koeficijent } \\
\text { difuzije } \\
\text { toplote } \\
\left(\mathrm{m}^{2} / \mathrm{s}\right)\end{array}$ \\
\hline 612 & 0 & 0,112 & 0 & 0,558 & $0,200 \times 10^{-6}$ \\
\hline 629 & 2,78 & 0,116 & 3,57 & 0,615 & $0,189 \times 10^{-6}$ \\
\hline 766 & 25,16 & 0,372 & 232,14 & 1,558 & $0,239 \times 10^{-6}$ \\
\hline 780 & 27,45 & 0,391 & 249,11 & 1,630 & $0,243 \times 10^{-6}$ \\
\hline
\end{tabular}

Rezultati merenja pokazuju enormno povećanje toplotne provodljivosti materijala sa povećanjem vlažnosti $u$ odnosu na suvo stanje materijala. Iz rezultata vidamo da $\mathrm{u}$ odnosu na suvo stanje materijala dolazi do povećanja toplotne provodljivosti $\lambda(\mathrm{W} / \mathrm{mK}$ ) za prirodno vlažno stanje koje u zimskom periodu može biti u zidu. To povećanje kod Ytonga iznosi 232,14 \% a kod pečene opeke iznosi 175,06 \%. Instrument Isomet 2114 je izmerio i Specifičnu toplotu c $\left(\mathrm{MJ} / \mathrm{m}^{3} \mathrm{~K}\right)$ koji je fizikalno potpuno logičan i opravdan jer sa povećanjem vlažnosti se povećava i Specifična toplota c vlažnog materijala (Tabela 2 $i$ Tabela 3). To je zbog toga jer voda ima najveću Specifičnu toplotu c $=4,186 \mathrm{MJ} / \mathrm{m}^{3} \mathrm{~K}$. Isto tako izmereni podatak o difuziji toplote pokazuje mnogo veće povećanje kod opeke sa povećanjem vlažnosti u odnosu na Ytong blok, kod koga je difuzija toplote neznatno povećana u odnosu na povećanje vlažnosti. To je potpuno logično, jer Ytong blok ima veliku poroznost koja onemogućava veliku difuziju toplote bez obzira na visinu vlažnosti materijala (Tabela 2 i Tabela 3 ).

Vlažnost materijala u spoljnjim zidovima na nivou koja je izmerena u prirodno vlažnoj sredini je moguća i to zavisi od načina i brzine gradnje objekta. Naime, u toku zidanja sa pečenim opekama i sa Ytong blokovima obavezno se elementi za zidanje moraju kvasiti sa vodom da ne izvlače vodu iz maltera za zidanje. U postupku malterisanja zidova, predhodno se zidovi opet moraju nakvasiti sa vodom da zidovi ne povlače vodu iz maltera za malterisanje. Ako se zidovi nisu dovoljno isušili a na njihovu spoljnju stranu se postavi termoizolacija od stiropora ili od vune sa lepkovima, vlaga će ostati u zidovima. U tom slučaju moguće je da zidovi imaju vlažnost koja je označena kao „vlažnost u prirodno vlažnoj sredini”. To znači da bi termoizolaciona sposobnost zidova bila enormno umanjena u odnosu na suvo stanje materijala. Ako je vlažnost zidova veća od ove vlažnosti u tablicama, to znači da će provodljivost toplote biti veća od one koju smo izračunali. Prolaz toplote će biti povećan u odnosu na izračunati a to znači da energetska klasa objekta neće biti zadovoljena.

\section{ZAKLJUČCI}

Iz navedenih rezultata istraživanja vrlo izvesno je da postoji ozbiljna sumnja da je vlažnost zidova (\%) znatno veća od one sa kojom se računa iz tabela, kada se toplotna provodljivost $(\mathrm{W} / \mathrm{mK})$ materijala povećava u odnosu na suvo stanje. To povećanje vrednosti toplotne provodljivosti $(\mathrm{W} / \mathrm{mK})$ obično iznosi od $15 \%$ do $30 \%$, u zavisnosti od vrste materijala. Druga nepovoljna okolnost postoji, da proizvođači materijala za 
građenje zidova i izolovanje, prikazuju vrednosti toplotne provodljivosti (W/mK) koje ne odgovaraju za vlažno stanje materijala, već isključivo za suvo stanje materijala, kako je i izmereno. Sa instrumentima starije generacije ispitivanje se vrši isključivo u suvom stanju materijala kada materijal pokazuje najbolji otpor provođenju toplote. Tada bi se pojavila kriva ocena energetske klase, jer bi gubitci energije bili veći od izračunatih. To može imati nesagledive posledice i sudske procese naknade štete kupcima nekretnina, stanova i poslovnih prostora, zbog neispunjavanja ugovorene klase energetske efikasnosti. Kako bi izbegli greške i eventualne štete, potrebno je da se pravilno odredi stvarna vlažnost koja se pojavljuje u zidovima u zimskom periodu. Merenje toplotne provodljivosti (W/mK) na materijalima koji će biti u zidovima se mora uraditi za datu vlažnost (\%) u materijalu sa instrumentima nove generacije koji su u stanju da izvrše merenje u vlažnom stanju materijala. Na taj način ćemo dobiti egzaktne i tačne rezultate koje koristmo u daljnjim proračunima za izračunavanje prenosa toplote $\left(\mathrm{W} / \mathrm{m}^{2} \mathrm{~K}\right) \mathrm{i}$ ukupnih gubitika energije na osnovu kojih dajemo realnu ocenu klase energetske efikasnosti objekata.

\section{ZAHVALNOST}

Ovaj rad je urađen u okviru Naučno-istraživačkog projekta III-42012, koji finansira Ministarstvo prosvete, nauke i tehnološkog razvoja Republike Srbije.

\section{LITERATURA}

[1] Kekanović M., Čeh A., Hegedis I.: Respecting the Thermodynamics Principles of the Heat Transfer - as the Most Important Condition for Achieving High Energy Efficiency in Buildings - Energy of the Ground and Heat Pumps - the Most Reliable Alternative Energy Source, " 3 "d IEEE International Symposium on Exploitation of Renewable Energy Sources",2011, pp. 79-84

[2] SRPS EN 1745 - Masonry and masonry products - Methods for determining design thermal values, (2009.)

[3] Правилник о енергетској ефикасности зграда, "Сл. гласник РС", бр. 61/2011

[4] Kekanović M., Šumarac D., Čeh A., Ćorić S.: Accumulation of solar energy around downhole heat exchangers, Zbornik radova sa konferencije IEEP 2011, Kopaonik 2011

\section{THERMAL CONDUCTIVITY OF MOIST AND WET MASONRY UNITS - AN IMPORTANT INFLUENCE IN ENERGY EFFICIENCY OF BUILDINGS}

Summary: This article suggests a very important detail, which affects the energy efficiency of buildings - the moisture content of the insulating materials. Older 


\section{$4^{\text {th }}$}

INTERNATIONAL CONFERENCE

Contemporary achievements in civil engineering 22. April 2016. Subotica, SERBIA

generation instruments measures the thermal conductivity of materials exclusively at the dry state. That way the thermal conductivity $\lambda_{m}(\mathrm{~W} / \mathrm{mK})-$ is measured in dry condition and the estimated value $\lambda_{r}(W / m K)$, for wet materials is calculated indirectly (from tables). Often designers in calculations, accidentally or intentionally, are using $\lambda_{m}$ $(W / m K)$ for the dry state of the material, the smaller the value, which gives a greater thermal resistance $R\left(m^{2} \mathrm{~K} / \mathrm{W}\right)$. The problem occurs when the materials moisture raise at winter, with increased thermal conductivity, which will directly have a negative impact on energy efficiency of buildings. Instruments of the new generation as Isomet 2114, are able to quickly and accurately measure the calculated value $\lambda_{r}(\mathrm{~W} / \mathrm{mK})$, for in-situ state of moisture of materials, which will be in real in the winter season in the masonry. In this way it is possible to more accurately determine the thickness of the layers of the wall to meet the designed values of overall heat transfer coefficient $U\left(W / \mathrm{m}^{2} \mathrm{~K}\right)$ for the real conditions of moisture of materials in the masonry.

Keywords: conductivity, heat transfer, energy efficiency 